DOI: https://doi.org/10.33739/2587-5434-2019-66-73

\author{
Tatyana Sidorova \\ Doctor of Philological Sciences, Professor \\ Northern (Arctic) Federal University named after M.V. Lomonosov \\ (Arkhangelsk, Russia) \\ e-mail: t.sidorova@narfu.ru
}

\title{
INTERPRETATION POTENTIAL OF PROPER NAMES IN DERIVATIVES FUNCTIONING IN A POLITICAL DISCOURSE
}

\begin{abstract}
The main goal of the study is to identify the role of derivational senses in actualizing the aesthetic code of a literary text. At the heart of the author's conception lies the idea that linguistic means, including derivational ones, become the basis for the formation of the aesthetic code of the text. Herewith a text is considered as a cognitive space. As the main approaches to the study of the material, interpretative and cognitive (within the framework of cognitive poetics) ones are used. A text is interpreted as a result of discursive activity, reflecting the language experience of the author as a representative of the people, of the society, as a linguistic personality, and the derivational means in the artistic text become the embodiment of author's ideas, motives, images, attitudes, intentions, thus actualizing the aesthetic code. The factors of actualization of the aesthetic code are revealed, and the role of derivational meanings in its formation is proved.
\end{abstract}

Key words: derivational sense, motivation code, aesthetic code, factors of interpretation of meaning, textual motivation.

\section{T. А. Сидорова}

Доктор филологических наук, профессор

Северный (Арктический) федеральный университ имени М. В. Ломоносова, (Архангельск, Россия)

e-mail: t.sidorova@narfu.ru

\section{ИНТЕРПРЕТАЦИОННЫЙ ПОТЕНЦИАЛ ИМЁН СОБСТВЕННЫХ В ПОЛИТИЧЕСКОМ ДИСКУРСЕ}

\begin{abstract}
Аннотация. Основная цель исследования - изучение функционирования имён собственных как языковых знаков в реальном процессе номинации и использовании производных от них в политическом дискурсе. В основе нашей концепции лежит идея о том, что имена собственные, функционирующие в политическом дискурсе в качестве производящих основ, становятся одновременно маркером социокультурного кода как системы ценностей и транслятором языкового кода как системы языковых знаний. В процессе исследования реализуется когнитивный подход, при котором в центре внимания оказываются прагматический, социокультурный, коммуникативный и когнитивный аспекты политического дискурса как среды функционирования производных от имён собственных. Доказывается полифункциональность имён собственных, их специфика функционирования в политическом дискурсе.
\end{abstract}


Ключевые слова: имя собственное, производное слово, соииокультурный код, политический дискурс, когнитивно-дискурсивный анализ, структура знания, коммуникативнопрагматический аспект, языковой код

\section{ВВЕДЕНИЕ}

Актуальность исследования детерминируется возрастающим вниманием к изучению языковых фактов в аспекте когниции и коммуникации, а также необходимостью углубленного анализа механизмов словопроизводства на базе имён собственных как наиболее яркого процесса, характеризующего современный политический дискурс. Объектом исследования являются производные от фамилий, функционирующие в политическом дискурсе. Предмет исследования - имена собственные (фамилии) как способ познания и оценки действительности, воплощающие новые структуры знаний в качестве производящих основ. Материал исследования - авторская картотека, содержащая свыше 2000 производных, образованных от фамилий известных политических деятелей и представленных в высказываниях политического дискурса, выделенных методом сплошной выборки из текстов современных газет, телепередач, ресурсов Интернета. Следует также отметить, что исследование того или иного вида дискурса - одно из перспективных направлений современной лингвистики, поскольку процессы изменения в социокультурных практиках тут же отражаются в дискурсивных практиках. Политический дискурс отличается усилением личностного начала, ориентацией на привлечение внимания адресата, опорой на ценностную картину мира народа. Поэтому особенно актуальным становится изучение специфики имён собственных, функционирующих в политическом дискурсе в качестве производящих основ, поскольку обращение к ним становится средством социального воздействия на сознание адресата. Апелляция к имени собственному - это не столько апелляция к прецедентному имени, сколько к оценке деятельности носителя имени (фамилии), его поступков, поведения в политической жизни.

В контексте производных слов как среды функционирования имена собственные концептуализируют новую социокультурную информацию. Известно, что значение слова имеет социокультурную природу и является конвенциональным. Значение производного от имени собственного формируется носителем лингвокультуры и обусловлено индивидуальным восприятием мира. Кроме того, на формирование нового смысла влияют экстралингвистические факторы. Так формируется «идентифицирующая интерпретация как процесс вторичной номинации, когда языковая единица фиксирует новый фрагмент знания. Языковая единица, служащая инструментом идентификации, увеличивает свой денотативный потенциал и начинает обозначать новый класс объектов» (Boldyrev 2013). В производных от имён собственных инструментом идентификации является корневой морф, изоморфный фамилии. Поскольку в таких производных представлено вторичное осмысление действительности, их значение опосредовано дважды: языком и сознанием носителя лингвокультуры.

Какие знания концептуализируют производные от имён собственных? Как соотносятся дискурсивные функции производных с различными видами знаний? Как осуществляется переход с языкового кода на дискурсивный? Какие механизмы лежат в основе познавательных процессов? Все вопросы взаимосвязаны и соотносятся с глобальной проблемой «язык - мышление - сознание». Основная задача данного исследования - показать важную 
роль имён собственных как интерпретирующего фактора познания и оценки в процессе формирования и восприятия концептуального пространства политического дискурса, а также в структурировании системы репрезентации знаний. Так как язык является когнитивной системой, каждая языковая единица, в том числе и производные от имён собственных, выполняет наряду с другими и когнитивную функцию, т. е. участвует в процессе познания. Политический дискурс фиксирует языковой опыт говорящего (адресанта) как представителя той или иной социальной группы, а также - как языковой личности. В связи с этим производные от имён собственных не просто отражают абстрактную семиотическую систему, а становятся воплощением пресуппозиций, оценок, ценностных установок, идеологических ориентиров, политических идей адресанта. Говорящий (адресант) моделирует собственную языковую картину мира в дискурсе, используя для этого и производные от имён собственных. При этом нейтральный компонент - корень, изоморфный имени собственному, - трансформируется в интерпретирующий, поскольку вызывает рефлексию у адресанта и адресата.

\section{ОБЗОР ЛИТЕРАТУРЫ}

Проблема интерпретации имён собственных в качестве производящих тесно связана с проблемой семантического статуса имени собственного. В 60-е - 70-е годы XX века эта проблема решалась далеко неоднозначно. Одни учёные считали, что имена собственные вообще не имеют значения (А. A. Beletskiy, K. A. Bulakhovskiy, G. O. Vinokur Yu. A. Karpenko, A. A. Reformatskiy, N. I. Tolstoy, V. I. Chernyshyov etc.). Другие отстаивали наличие значения у имён собственных (V. I. Bolotov, V. D. Bondaletov, I.A. Vorobyova, L.P. Stupin, L.M. Shchetinin etc.). Например, Л. П. Ступин писал: «...имена собственные, кроме индивидуальных понятий, которые образуются в конкретном акте речи, выражают ещё и общие понятия, ибо они, как правило, всегда соотносятся в языке с определённым классом предметов» (Stupin 1969). Согласно третьей точке зрения имена собственные не имеют значения на языковом уровне, но в процессе употребления (референции) их значение формируется. Этой точки зрения придерживаются Э.С. Азнаурова, Д. Н. Арутюнова Е. Курилович, А. В. Суперанская, Н.В. Подольская и др. В настоящее время учёные признают наличие семантики у имён собственных, отмечая при этом её специфику. См., например, статью Е. А. Нахимовой (Nakhimova 2010). Мы считаем, что специфика денотативного компонента значения, например, антропонима, в наличии одного денотата, причём в языке денотат изолирован от имени, а в речи они в единстве. Специфика сигнификативного компонента значения в двойственности: в речи понятие, заключённое в антропониме, конкретно, а в языке абстрактно. Специфика структурного компонента значения заключена в способности антропонима называть лицо, характеристики которого социальны. Поскольку в политическом дискурсе функционируют в основном производные от фамилий, можно констатировать, что в конкретном дискурсе или ситуации фамилия приобретает дополнительные смысловые оттенки, но контекстная ситуация лишь конкретизирует семантический потенциал имени собственного. Следовательно, имея значение в языке, фамилия в конкретном дискурсе раскрывает свою смысловую сторону.

Словопроизводство на базе имён собственных - постоянный процесс, который был объектом целого ряда многоаспектных научных исследований (O. I. Aleksandrova, L. A. Vvedenskaya, N.D. Golev, V. P. B. П. Danilenko, N. P. Kolesnikov, D. C. Mgeladze A. V. Superanskaya, L.M. Shchetinin etc.). Особенно популярной стала книга Д.С. Мгеладзе, Н. 
П. Колесникова (Mgeladze and Kolesnikov 1970). В настоящее время в работах, посвящённых семантике производных от имён собственных, затрагиваются не только собственно языковой, но и когнитивно-дискурсивный аспекты номинации (L..V. .Babina, I.V. Bochkaryova, L. V. Ratsiburskaya, E. M. Pozdnyakova, A. S. Shcherbak etc.). Однако следует отметить, что большинство работ посвящено особенностям функционирования имён собственных как производящих основ в системе словообразования английского языка (L. V. Babina, I. V. Bochkaryova, E. O. Parshina, M.K. Sharashova, G. M. Shutkina etc.). Особого внимания заслуживают работы Л. В. Бабиной, И.В. Бочкарёвой и Е. М. Поздняковой (Babina and Bochkaryova 2011, Babina and Bochkaryova 2010, Pozdnyakova 1999).

Несмотря на достаточно большое количество работ по проблемам образования производных на базе имён собственных, не получили достаточного освещения прагматический, социокультурный и когнитивный аспекты их изучения в политическом дискурсе. Интерпретационный потенциал имён собственных в таких производных не был предметом специального изучения.

\section{МЕТОДЫ ИССЛЕДОВАНИЯ}

В соответствии с задачами исследования реализуются такие методы как собственно лингвистические (компонентный анализ, лингвостилистический, словообразовательный анализ, морфемный анализ, лингвосмысловой анализ текста); общегуманитарные (интерпретационный анализ, контекстуальный анализ); когнитивные (метод реконструкции структур знаний, метод концептуальной деривации, анализ пресуппозиций и др.), дискурс-анализ. Основным является когнитивно-дискурсивный подход.

Теоретико-методологическую основу нашей работы составили исследования в сфеpax теории концептуальной деривации (L. V. Babina, N. N. Bondarko H.Н. Бондарко, Е. K. Kubryakova, V. I. Zabotkina, O. K. Iriskhanova, E. M. Pozdnyakova etc.), теории интерпретации (G. I. Bogin, N. N. Boldirev, A.V. Bondarko, M. Berk, K.A. Dolinin etc. ), когнитивной лингвистики (N. N. Boldirev, V. Z. Demyankov, V. I. Karasik, E. K. Kubryakova, Z. D. Popova, G. Lakoff, R. Leneker, M. Minskiy, G. Soerl, Ch. Fillmor, U. Chief etc.), теории дискурса (M. M. Bakhtin, M. R. Zheltukhina, M. A. Kulinich, M. L. Makarov М.Л. Макаров, М. Yu. Oleshkov, A. P. Chudinov, T. A. Van Deik, L. V. Tsurikova etc.), теории когнитивнокоммуникативной парадигмы лингвистики (V. I. Karasik, G. G. Slyshkin, M. Yu. Oleshkov, A. N. Prikhod'ko etc).

\section{РЕЗУЛЬТАТЫ И ДИСКУССИЯ}

В когнитивной лингвистике значение не является семантической репрезентацией одного концепта, связывающего объект мира и слово. Это особенно хорошо прослеживается в производных от имён собственных, вызывающих ассоциации с огромным количеством концептов и концептуальных сфер. В научной литературе имена собственные известных политических, государственных деятелей, учёных, писателей, артистов относятся к репрезентантам этномаркированных концептов, а производные от них описываются как результат вторичной концептуализации (Look for example researchs of L.V. Babina, I. V. Bochkaryova, E. O. Parshina, E. M. Piozdnyakova, A. S. Shcherbak ). На наш взгляд, вторичная концептуализация имён собственных формирует их смысловую сложность. Новые смыслы актуализируются окказиональной сочетаемостью морфем в производном слове, нарушением синтагматических и парадигматических связей морфем и самих слов, влиянием контекста, экспрессивиза- 
цией производного. Интерпретационный потенциал производящей фамилии практически зависит от степени социальной значимости личности, стоящей за ней, сферы деятельности, фонетического облика фамилии, коннотаций, специфики функционирования производного слова в том или ином дискурсе. Зачастую адресант сам объясняет значение такого производного. Ср.: Одни новоявленные ублюдки-запутинцы и замедведевцы поют осанну своим угнетателям и сооружают им памятники, другие жульничают на выборах и в судах, а третьи забивают до смерти своих братьев по классу и народных заступников-правдоборчев, разрушают памятники вождям трудящихся и защитникам отечества. При этом проверенный метод ублюдизации - путинизации всей страны как процесс агрессивного насаждения культа личности исторически несостоятельного политического деятеля будет сохраняться посути, переходя в форму медведизации страны (Николай Яценко. Правитель слабый и лукавый. Газета «Родина» от 23 апреля 2009 г. № 17 (762). Два первых производных «запутинцы» и «замедведевцы» осмысливаются в контексте как 'сторонники Путина и Медведева, те, кто поддерживает политику, проводимую ими'. В дискурсе производные приобретают негативную оценку: ублюдки ('люди с низкими животными инстинктами'). В контексте это беспринципные люди, полностью подчинившиеся власти, раболепствующие, нарушающие принципы морали и права. Корневые морфемы, изоморфные фамилиям Путин и Медведев, приобретают негативные коннотации. Префикс 3А- в производных актуализирует сему 'одобрения' политики президента. Реализуется оценочная пресуппозиция - сторонники Путина и Медведева являются ублюдками. Производные «путинизация» и «медведизация» объясняются адресантом как процесс агрессивного насаждения культа личности исторически несостоятельного политического деятеля. Логическая пресуппозиция - агрессивное насаждение культа личности президента порождает ублюдков (запутинцев и замедведевцев). Сема 'процессности' манифестируется суффиксом - ИЗАЦИЙ-. Характеристика процесса манифестируется корнем, изоморфным фамилии, и ближайшим речевым контекстом (ублюдизация). В сознании адресата может возникнуть и прагматическая пресуппозиция - рыба гниёт с головы. А. В. Бондарко одним из аспектов языкового значения выделяет интерпретационный компонент как способ представления смысла, связанного с данной формой (Bondarko 1996). Таким интерпретационным компонентом в производных от имён собственных являются корневые морфемы как репрезентанты внутренней формы слова. Они являются этнокультурно маркированными компонентами мотивационной структуры. Например, в производных «ельцинизм», «гайдарономика», «жириновщина» объективируются образыпрототипы известных политических деятелей России. При этом профилируется та или иная конкретная пропозиция, связанная с носителем фамилии.

Производные от имён собственных маркируют дискурсивный характер ментального компонента внутренней формы, поскольку за производящим стоит не сама личность, а поступок, характер поведения, политическое событие, ситуация, пресуппозиция, оценка личности и т. п. В основе такого словопроизводства лежит особый мотивационный код (Sidorova 2012): концептуальная сфера ЧЕЛОВЕК взаимодействует с другими концептуальными сферами. Совмещение разных концептуальных сфер включает когнитивный механизм концептуальной деривации, в результате чего возникает новая структура знания. Мы придерживаемся ономасиологического подхода к словообразовательному значению, согласно которому оно не является суммой значений составляющих компонентов, а осмысливается как значение модели в целом. 
Производящая фамилия известного политического деятеля может приобрести модальные коннотации, которые становятся основанием для развития новых смыслов у производного. Например, специальный репортаж Петра Любимова на ТВЦ от 12 ноября 2018 года был назван «Трамплантация Америки». Концептуальная структура производного «трамплантация» передаёт идею связи с прецедентным именем - фамилией американского президента, за которым стоит конкретная социокультурная ситуация. В сознании адресата возникают ассоциации, связанные с президентством Дональда Трампа: борьба с мигрантами, рост производства внутри страны, снижение безработицы и т.п. Известно, что в США в этот период созрела острая политическая ситуация, которая отражается и на внешней политике. В стране столкнулись два лагеря. Трамп изменяет ситуацию, несмотря на сопротивление со стороны противоположного лагеря. Он хочет снова сделать Америку великой. Противоположным лагерем Трамп воспринимается как неуправляемый президент, которого поддерживает народ. В качестве метаконцептов как факторов интерпретации производных от таких имён собственных являются ЦЕННОСТЬ, ОЦЕНКА, НОРМА, СТЕРЕОТИП, СТАТУС. Механизм концептуальной деривации производного «трамплантация» базируется на совмещении концептуальной сферы МЕДИЦИНА и концептуальной сферы ПОЛИТИКА. Логическая пресуппозиция текста репортажа - Америка нуждается в кардинальном изменении политической ситуаџии, а Трамп является субъектом (инициатором) этих изменений. Пропозиции событийные: В Америке существует фальшивая экономика, в Америке тяжёльй кризис, закрываются предприятия внутри страHbl, paстёт безработииа, повышается процен мигрантов. Производное «трамплантация» осмысливается в контексте репортажа как 'действия президента Трампа, направленные на улучшение (оздоровление) внутренней социально-экономической ситуации в Америке'. Производящий компонент попадает в чуждую концептуальную среду, в результате чего происходит сближение процессов концептуализации и формирования значения производного.

Собранный нами материал показывает, что отнесение прецедентных имён к «вербальным компонентам когнитивной базы» (Krasnyh 1998) нуждается в корректировке. Наряду с прецедентными текстами и ситуациями прецедентные имена относятся к «вербализуемым феноменам» (а не «вербальным») и входят в когнитивную базу как инварианты восприятия. В конкретном дискурсе, функционируя в качестве производящих основ, прецедентные имена обрастают новыми концептуальными признаками и смыслами. Если языковое словообразовательное значение является специальной формой выражения языкового сознания, то дискурсивный смысл производных, образованных от имён собственных, - это форма выражения когнитивного сознания адресанта. Дискурсивный смысл таких производных аксиологичен, поскольку детерминируется ценностными установками адресанта. Заимствованные имена собственные, в том числе и фамилии, могут стать маркерами национальной системы ценностей и стереотипов сознания.

Производные от фамилий политических и государственных деятелей очень часто в политическом дискурсе становятся базой для модусной категоризации. Например, фамилия президента России часто в политическом дискурсе становится основой для формирования производных с негативной оценочной функцией. Ср.: А путинизм как социально опасное явление, суть которого заключается в том, что вербальным прикрытием народного заступничества правящий режим проводит политику погубления своего народа, будет плавно заменяться (если народ не скажет решительно: СТОП!) своей новой, ещуё более циничной и 
масштабной разновидностью - медведизмом (Николай Яценко. Правитель слабый и лукавы. Газета «Родина» от 23 апреля 2009 г. № 17 (762). Суффикс -изм- репрезентирует сему 'идеология'. В контексте появляется новая сема 'социальное явление'. Автор объясняет это социальное явление как осуществление политики погубления своего народа. Логическая пресуппозиция, стоящая за высказыванием, - Путин проводит политику погубления своего народа. Прагматическая пресуппозиция: Нельзя говорить одно, а делать другое. Реализуется апелляция к негативной оценке: сочиально опасное явление, более ичиничная и масштабная разновидность. Производное «путинизм» концептуализирует смысл 'антинародная политика Путина', «медведизм» соответственно означает 'антинародная политика Медведева'. Это ещё и 'социально опасное явление'. Синтагматические связи производных (социально опасное явление, политика погубления своего народа, ещё более циничная и масштабная разновидность) маркируют негативное отношение автора к политикам, чьи фамилии стали базой для производных. Слова «путинизм» и «медведизм» вызывают рефлексию у носителей лингвокультуры: связь с именами президента, премьер-министра и политической ситуацией.

\section{ЗАКЛЮЧЕНИЕ}

Таким образом, при формировании производных от имён собственных, в частности фамилий, важную роль играют такие факторы, как социальная детерминированность производного, общественная значимость носителя фамилии, фонетический облик фамилии, коммуникативная цель адресанта политического дискурса, его ориентация на национальные ценности, аксиология и модус дискурса. Стратегиями номинации в таких производных становятся логические (рациональные), образные, оценочные, рефлексивные, модальные. Коммуникативные стратегии разнообразны, но доминируют игровые, эмоционального воздействия и оценки. Смысл производных от фамилий, формируется когнитивными и языковыми механизмами, а также пресуппозициями политического дискурса как среды функционирования производных. Чем шире коннотативный фон производящего имени собственного, тем богаче его интерпретационный потенциал и деривационная валентность. Идейная направленность политического дискурса поддерживает коннотации производящей фамилии. Знания, стоящие за производными от фамилий, носят инферентный характер. Производящая фамилия актуализирует наиболее существенные для адресанта признаки концептосферы фамилии как прецедентного феномена.

\section{REFERENCES}

Babina, L.V., Bochkaryova, I.V. (2011). Kognitivnye osnovaniya proizvodnyh slov, obrazovannyh ot imyon sobstvennyh [Cognitive bases of derivatives formed from proper names] // Voprosy kognitivnoj lingvistiki. - Tambov, (3), 56-64.

Babina, L.V., Bochkaryova, I.V. (2010) Semantika proizvodnyh slov, obrazovannyh ot imyon sobstvennyh prefiksal'nym sposobom: kognitivnyj aspekt [Semantics of derivatives formed from proper nouns in the prefix way: cognitive aspect]// Vestnik Severo-Osetinskogo gosudarstvennogo universiteta. Obshchestvennye nauki. Vladikavkaz, (3), 69-74.

Boldyrev, N.N., Panasenko, L.A. (2013) Kognitivnaya osnova leksicheskih kategorij i ih interpretiruyushchij potencial [Cognitive basis of lexical categories and their interpretive potential] // Voprosy kognitivnoj lingvistiki, (2), 5-12. 
Bondarko, A.V. (1996) Problemy grammaticheskoj semantiki i russkoj aspektologii [Problems of grammar semantics and Russian aspectology]. S.-Peterburg: Izdatel'stvo S.-Peterburgskogo universiteta, $218 \mathrm{~s}$.

Krasnyh, V.V. (1998) Virtual'naya real'nost' ili real'naya virtual'nost'? (CHelovek. Soznanie. Kommunikaciya) [Virtual reality or real virtuality? (Person. Consciousness. Communication)]. Monografiya: Dialog - MGU, s. 81.

Mgeladze, D. S., Kolesnikov, N.P. (1970) Ot sobstvennyh imyon k naricatel'nym. Slova antroponimicheskogo proiskhozhdeniya $\mathrm{v}$ russkom yazyke [From proper names to common nouns. Words of anthroponymic origin in the Russian language], Tbilisi: Izd-vo Tbil. universiteta, $193 \mathrm{~s}$.

Nahimova, E.A. (2010) Diskussiya o statuse i semantike imeni sobstvennogo [Discussion on the status and semantics of the proper name]// Politicheskaya lingvistika, (1), 171-174.89.

Pozdnyakova, E.M. (1999) Kategoriya imeni deyatelya i puti eyo sinhronnogo razvitiya v kognitivnom i nominativnom aspekte (na materiale anglijskogo yazyka) [Category of the agent's name and ways of its synchronous development in the cognitive and nominative aspect (on the material of the English language)]: Dis...d-ra filol. nauk: 10.02.04 -. Germanskie yazyki. Moskva, $318 \mathrm{~s}$.

Sidorova, T.A. (2012) Kognitivnyj aspekt tradicionnyh problem slovoobrazovaniya i morfemiki: monografiya [Cognitive aspect of traditional problems of word formation and morphemics]. Arhangel'sk: OAO SOLTI, $480 \mathrm{s.}$

Stupin, L. P. (1969) O leksicheskom znachenii imyon sobstvennyh // Voprosy teorii i istorii yazyka [On the lexical meaning of proper names]. Leningrad: Izdatel'stvo Leningradskogo universiteta, 216-225.

Information about the author: Tatyana Sidorova - Doctor of Philological Sciences, professor, Northern (Arctic) Federal University named after M.V. Lomonosov (Russia) e-mail: t.sidorova@narfu.ru

Сведения об авторе: Татьяна Александровна Сидорова - доктор филологических наук, профессор кафедры русского языка и речевой культуры Северного (Арктического) федерального университета имени М. В. Ломоносова, (Россия) e-mail: t.sidorova@narfu.ru

Manuscript received: 11/15/2018

Accepted for publication: $01 / 25 / 2019$

Рукопись получена: 11/15/2018

Принята к печати: 01/25/2019 